\title{
Acción territorial y construcción del desarrollo. La experiencia de zonas rurales de la Pampa argentina
}

\author{
Territorial action and construction of development. The \\ experience of rural areas of the Argentine Pampa
}

\author{
Marcelo Silip
}

\begin{abstract}
RESUMEN
Este trabajo analiza las formas y los mecanismos con que los múltiples actores involucrados en un territorio generan acciones en vistas a construir el futuro. Para poder eludir el uso del concepto de desarrollo como marco referencial, este trabajo moviliza el concepto de acción territorial, por entender que el mismo permite analizar más cabalmente las formas con que múltiples actores, con diversas y a veces contradictorias representaciones acerca del futuro, ponen en marcha iniciativas para construir y gestionar sus territorios. Esta propuesta conceptual y metodológica se pone en práctica en un territorio rural de la Pampa argentina, territorio que ha vivido procesos de transformación similares a los de otras regiones del país, y que por lo tanto puede ser considerado un modelo representativo, no sólo de transformaciones territoriales, sino también de mecanismos y formas de construir la acción pública, privada y colectiva en torno a un proyecto de futuro territorial.
\end{abstract}

Palabras claves: acción territorial, desarrollo territorial, representaciones sociales, actores, Argentina.

\begin{abstract}
This work analyses the forms and mechanisms with which the multiple actors involved in a territory generate actions in order to build the future. In order to avoid the use of the concept of development as a referential framework, this work mobilizes the concept of territorial action, because it allows us to analyses more fully the ways in which multiple actors, with diverse and sometimes contradictory representations about the future, put into march initiatives to build and manage their territories. This conceptual and methodological proposal is put into practice in a rural area of the Argentinian Pampas, a territory that has undergone processes of transformation similar to those of other regions of the country, and that therefore can be considered a representative model, not only of transformations territorial, but also of representations of the future on the part of their actors and models of intervention by public, private and collective action.
\end{abstract}

Keywords: territorial action, territorial development, social representations, actors, Argentina.

Consejo Nacional de Investigaciones Científicas y técnicas (CONICET) - Universidad Nacional del Sur, Departamento de Geografía y Turismo, Bahía Blanca, Argentina. Email: Sili.marcelo@gmail.com 
Los procesos y las políticas de desarrollo local y regional son temas arduamente analizados y trabajados en el contexto de América Latina en el último medio siglo. Hay tres grandes razones que sostienen esta fuerte preocupación, en primer lugar porque existe una clara necesidad de mejorar la calidad de vida en numerosas zonas de esta vasta geografía de América Latina, zonas donde persisten todavía elevados niveles de pobreza y marginalidad. En segundo lugar porque es necesario también reducir las brechas de ingresos y calidad de vida entre regiones en los países, América Latina se ha caracterizado históricamente por mantener niveles de desigualdad territorial muy elevados, con regiones muy pobres y marginales y otras regiones más dinámicas con mayores niveles de ingreso y calidad de vida, estas profundas desigualdades contribuyen también a mantener y consolidar los grandes problemas estructurales de la región (deseconomías de escala, mantenimiento de altos niveles de violencia e inseguridad, deterioro de recursos naturales, etc.). En tercer lugar, las políticas de desarrollo local y regional aparecen como la fórmula para alcanzar estándares y niveles de modernización comparables a los países de Europa Occidental o de América del Norte.

Esta preocupación por el desarrollo, se traduce en la puesta en marcha de numerosas iniciativas de desarrollo ${ }^{2}$ (planes, programas y proyectos de desarrollo o acciones individuales) que tienen como objetivo captar nuevas oportunidades para el territorio, como pueden ser la promoción de emprendimientos productivos, la construcción de infraestructuras y equipamientos, la animación cultural, u otro tipo de iniciativas tanto formales y estructuradas dentro de un plan, como informales sin conexión con otras actividades. Todas estas iniciativas surgen desde los gobiernos locales, provinciales y nacionales, o también desde sectores sociales y productivos, a través de organizaciones sociales o empresariales.

Más allá de quién pone en marcha estas iniciativas y de la naturaleza de las mismas, la evidencia en la región, muestra que hay dos elementos distintivos en torno a las mismas. En primer lugar ellas se generan y gestionan con un bajo nivel de coordinación, con superposición, conflictos y competencia entre ellas, lo cual lleva a la pérdida de eficacia y de impacto (Riffo, 2013), así muchas veces en un mismo territorio, múltiples actores ponen en marcha iniciativas que entran en conflicto unas con otras, o se superponen esfuerzos y se dilapidan recursos debido a la duplicidad de las mismas. Un segundo elemento es que los actores involucrados en la puesta en marcha de estas iniciativas tienen una clara divergencia sobre el significado y las representaciones en torno al desarrollo y por ende sobre los objetivos que persiguen las acciones puestas en marcha (Iparraguirre, 2017), esto torna más confuso los objetivos y el modelo de futuro a seguir.

Esta falta de coordinación y esta divergencia o falta de consenso en torno a los objetivos de "desarrollo" de un territorio, puede ser observada en múltiples escalas territoriales, desde los niveles nacionales, hasta los locales, lo cual define todo un nuevo escenario territorial de fragmentación, caos y mayor complejidad sociopolítica. Dentro de este nuevo contexto histórico, los tradicionales enfoques y modelos de intervención, pensados para territorios ya estructurados, con políticas jerárquicas, con roles y funciones claramente definidos, y con un modelo de moder-

En términos genéricos se entiende en este trabajo al desarrollo como la mejora sistemática y progresiva de las condiciones de vida de la población, con un crecimiento económico y del empleo, con una mejora educativa y cultural de la población y una mayor sostenibilidad de los recursos naturales y el paisaje. 
nización y crecimiento claramente definido y socialmente aceptado, ya no generan los resultados esperados (Sili, 2016).

Teniendo en cuenta este nuevo escenario signado por la globalización, la complejidad de procesos y la fragmentación de la acción pública, privada y colectiva, este artículo tiene como objetivo mostrar como los diferentes actores involucrados en un territorio construyen sus acciones en vistas a un ideario de desarrollo. Interesa entender las acciones puestas en marcha en un territorio, la organización de los actores involucrados, las representaciones que estos actores claves tienen en torno al futuro del territorio, las vinculaciones de estas iniciativas y los actores con otros niveles escalares (con las propuestas de orden regional y nacional) y con otras iniciativas, y por que, a pesar de todos los esfuerzos que se realizan, los impactos de estas iniciativas suelen ser muy pobres.

La hipótesis que sustenta nuestro trabajo es que en muchos territorios, a pesar que se ponen en marcha en forma permanente, múltiples iniciativas por parte de diferentes actores, estas no generan los resultados planteados o esperados. Esto se debería a tres factores,

1. en primer lugar porque los territorios no logra consensuar una visión y proyecto compartido de futuro,

2. en segundo lugar porque se genera una profunda fragmentación y desarticulación entre los actores involucrados en el territorio, producto de fuertes diferencias en las representaciones que tienen sobre el sentido del desarrollo, en las lógicas de actuación y en las rítmicas sociales de los actores (Iparraguirre, 2017) y

3. por último porque no hay operadores territoriales capaces de acompañar en la construcción y gestión de un proyectos territorial (Landel et al. 2011).

Para poder dar cuenta de estos procesos y esta hipótesis de trabajo, se analiza un caso específico de nivel local en la Pampa argentina, un territorio que puede ser considerado como un modelo representativo de acción territorial. Moviliza este trabajo un doble objetivo, en primer lugar generar nuevos conocimientos sobre las formas como las sociedades ponen en marcha, sobre la base de una fuerte diversidad de representaciones del desarrollo, sus iniciativas generadoras de un orden territorial ${ }^{3}$, y en segundo lugar definir un modelo analítico de las formas y procesos de construcción territorial ${ }^{4}$, susceptible de ser replicado en otros ámbitos territoriales.

Diferentes perspectivas conceptuales pueden ser planteadas para este tipo de análisis, la más tradicional se fundamenta en el "public management" en su versión anglosajona (Gruening, 2001) y en la "action publique territoriale" en su versión francesa (Douillet, et al. 2015; Landel et al., 2011). Estas perspectivas conceptuales pueden sustentar el análisis del rol del Estado y de

\footnotetext{
3 Por orden u organización territorial se hace referencia a las formas como el territorio esta estructurado. Tal como lo afirma Brunet “El espacio terrestre esta organizado y nosotros podemos descubrir ese orden que le impuso la sociedad que lo produjo y lo transforma. Este orden proviene del trabajo cotidiano de actores individuales, instituciones públicas y actores colectivos que aseguran, crean o modelan las grandes orientaciones y los trazos estructurales que afectan los territorios" (Brunet et al. 1993, pag. 359) (traducción del autor)

4 En este trabajo se entiende a la construcción territorial como el proceso de apropiación material y simbólica de un espacio geográfico y de organización del mismo para dotarlo de un sentido para la sociedad que lo ocupa. Esta apropiación es material cuando se ocupa el territorio, es simbólica cuando se construye una identidad en torno al mismo y se lo organiza cuando se le impone un orden, que puede ser una construcción informal o puede estar regido por un plan (plan de urbanismo o plan de ordenamiento territorial por ejemplo).
} 
las políticas públicas en la construcción y la organización del territorio, un indicador de ello es que gran parte de la producción científica de las últimas décadas ha estado sustentada en esta perspectiva. Sin embargo, la profunda transformación operada en el contexto latinoamericano y argentino, la globalización y la descentralización de por medio (CEPAL, 2016), han definido un nuevo contexto en el cual los operadores del cambio territorial ${ }^{5}$ no son sólo el Estado, sino, y cada vez más, los actores privados (empresas especialmente) y los actores colectivos (organizaciones sociales, cooperativas, etc.). Teniendo en cuenta esta nueva realidad, es necesario una base conceptual más amplia que permita comprender el rol y el accionar de múltiples actores, es por ello que se apela al concepto de acción territorial como soporte conceptual y metodológico para el análisis (Sili, 2018).

Para poder dar cuenta de estas hipótesis de investigación, se presenta en primer lugar un marco de referencia conceptual desde donde comprender los procesos de construcción territorial, luego se presenta la metodología utilizada para el análisis para pasar en tercer lugar a presentar el territorio de análisis. A posteriori se presenta un breve análisis de los escenarios de futuro planteados por los múltiples actores, lo cual permite observar las contradicciones en torno al deseo de futuro de los diferentes actores locales. Finalmente se presenta el análisis de las acciones territoriales, su dinámica y sus limitantes.

\section{La acción territorial como marco de referencia}

Entendemos al territorio como un espacio geográfico que carga con un conjunto de intencionalidades políticas, sociales, productivas, culturales (proyectos) que se plasman o concretan en función de las capacidades de los actores o los grupos de actores para llevarlas a cabo (capacidad de acción). Así, el territorio no es entonces un simple soporte físico, sino la "arena" donde los grupos sociales construyen un devenir, por lo tanto las características de estos territorios no van a depender sólo de sus condiciones naturales, ni de su configuración espacial, sino también de las formas en cómo se articulan entre sí los proyectos de cada uno de los actores y como a partir de esta articulación son capaces de valorizar y gestionar el lugar y construir un proyecto de futuro.

En función de esta concepción del territorio, la acción territorial puede ser pensada como el proceso dinámico a partir del cual los actores públicos, colectivos y privados construyen acciones de diferente índole, institucionalizados a veces en planes o proyectos de desarrollo o no, en vistas a organizar y gestionar sus territorios, en función de un ideario o modelo deseado de futuro, el cual no siempre esta explicitado, ni es hegemónico o compartido por el conjunto de los actores (Bustos Cara, 2008; Sili 2018). Estas acciones están estructuradas bajo un modelo de gobernanza, condicionadas por las normas o reglas formales e informales vigentes y el intercambio de recursos, que se caracterizan por ser escasos y estar inequitativamente distribuidos (Manzanal et al. 2012). 
Esta acción constructora de territorios integra el pasado dada la memoria y las estructuras físicas heredadas, el presente por las condiciones de contexto actuales y el futuro de acuerdo a las imágenes y representaciones que tenemos sobre ese futuro y que determinan las intencionalidades en la toma de decisiones. Esta construcción es relacional en el sentido que siempre integra y coordina necesariamente múltiples y diversas iniciativas de actores con lógicas de acción y ritmos de vida muy diferentes, pues todos los actores y los grupos sociales involucrados no necesariamente siguen las mismas lógicas y las mismas rítmicas culturales (Iparraguirre 2017), de allí que la acción territorial es también un claro generador de conflictos entre actores y grupos sociales, pues las acciones de unos muchas veces chocan o limitan las acciones de otros actores. Así, tal como lo plantea Bauman "Los hombres hacen su propia historia, pero no la hacen a su libre arbitrio, bajo circunstancias elegidas por ellos mismos, sino bajo aquellas circunstancias con que se encuentran directamente" (Bauman, 2017, p. 150). Si bien la acción territorial se construye a partir de una intencionalidad de los actores, y dado que estas intencionalidades son muy diferentes y no siguen un modelo de futuro deseado por todos por igual, los resultados del conjunto de las acciones en un territorio no siempre terminan configurando situaciones de mayor desarrollo, al contrario, en muchas ocasiones se generan situaciones de mayor desequilibrio, deterioro o empobrecimiento de los territorios, dado que pueden prevalecer acciones de carácter depredatorias, de explotación irracional de los recursos o de usos indebidos, por encima de acciones movilizadas por deseos de usos sostenibles o de gestión más racional de los recursos (Pouthier, 2013). Así, el análisis de la acción territorial es un poderoso instrumento para entender como se construyen los territorios y su devenir, pensando el futuro de los territorios de una manera más descarnada y real, sin caer en la trampa y la ilusión del trayectorismo occidental (Appadurai, 2015) por la cual los territorios están inevitablemente sujetos y condicionados a seguir una línea de tiempo que nos conduce a escenarios de superación y progreso, y que siempre implicó que toda política e intervención en los territorios debe servir necesariamente para remover los obstáculos que frenan o impiden avanzar hacia ese escenario predestinado de progreso. Al contrario, a través del análisis de la acción territorial podemos entender que los territorios también pueden evolucionar hacia escenarios muy diferentes, con deterioro ambiental y de la calidad de vida.

Los actores involucrados en la acción territorial pueden ser diferenciados en actores públicos, privados o colectivos. La acción pública es ejercida por aquellos sujetos que basan su propósito de intervención en el hecho de que representan a los ciudadanos, y se rigen por la estructura política administrativa del Estado. La lógica de acción implica actuar en función de aquellas alternativas que mejoren la capacidad para obtener consenso político, promoviendo los acuerdos y compromisos que sean necesarios. Los actores públicos están integrados por el gobierno, que representa el poder ejecutivo en los diferentes niveles de competencia; la burocracia y la administración pública, que ejecuta las decisiones gubernamentales; el parlamento y los órganos de justicia (Dente et al. 2014). Los actores privados en tanto reúnen a los individuos, empresas y corporaciones que intervienen en el territorio a partir de un interés específico que implica en muchas ocasiones la maximización de beneficios económicos o el logro de beneficios sociales o culturales. La dinámica que se haga preponderante en el territorio incidirá directamente sobre sus intereses, sea por los costes que implica afrontarla o por la posibilidad de incrementar alguna de sus posiciones en el espacio social (Bourdieu, 2005). Finalmente la acción colectiva, implica la integración de distintos actores en forma de asociación para asumir la representación de intereses que no pueden actuar por ellos mismos, tales como la salud, la educación, la igualdad, la protección del medio ambiente, la seguridad, la lucha contra la pobreza, etc.. Estos intereses ge- 
nerales suelen estar lejos de encontrarse entre los prioritarios de los actores políticos y privados, por lo que pujan por sus propios mecanismos de participación (Crozier et al., 1977). El propósito de intervención busca contribuir al bien común, incorporando ciertas estructuras organizativas que asumen la tutela de intereses generales y los representan en las distintas instancias que se requiera para evitar que sean desatendidos (Bustos Cara, 2008; Dente et al. 2014).

Las acciones territoriales pueden tener diferentes niveles de complejidad, hay acciones territoriales que pueden ser consideradas como iniciativas cotidianas de los actores en términos individuales (Moine et al., 2013) y con baja capacidad para estructurar cambios en el corto plazo, estas acciones cotidianas que "no surgen necesariamente de un plan consciente, sino simplemente de lo que la gente hace, siente, percibe y llegan a articular en su búsqueda de significado para su vida cotidiana" (Harvey, 2013, p. 15). En el mismo sentido Gumuchian y otros plantean "el territorio debe ser pensado a través de un conjunto de microeventos, entendiendo por microeventos las actitudes y los comportamientos de los actores en el territorio" (Gumuchian et al., 2003, p. 48). Muchos de estos microeventos o acciones individuales o colectivas producen resultados cuya dimensión territorial es menor, sin embargo la red de estas acciones se transforman en un momento dado o confluyen en la construcción de un proyecto territorial. Pero también hay acciones territoriales de mayor complejidad y envergadura, con gran capacidad para estructurar cambios territoriales, llevadas a cabo por uno o múltiples actores y con más fuerza y capacidad para organizar y estructurar el territorio, históricamente estas acciones fueron planificadas, pautadas y organizadas por los gobiernos.

Las acciones pueden ser diferenciadas según el tipo o naturaleza de las mismas. Puede ser de desarrollo económico, producción y empleo, de carácter sociocultural, acciones político institucionales, de gestión ambiental, de creación de infraestructuras o de ordenamiento territorial.

Finalmente, un último aspecto que es necesario observar en las acciones territoriales, son los recursos que movilizan cada grupo de actores involucrado en las mismas. Subirats (2008, p. 94) definen recurso como "un activo de materias primas de las que los actores públicos y privados se sirven para llevar a cabo sus acciones". Es importante tener en cuenta que no existen recursos de los territorios "en sí", sino que estos surgen de la intencionalidad, la movilización y la cooperación de los actores que con cierto grado de autonomía los construyen a partir de su relación con el sistema de producción (Kebir, 2006; Landel et al. 2011). Así, cada sujeto territorial estructurado por diferentes elementos de la economía, la cultura y la naturaleza, interactúa con los bienes que le vienen dados (fauna, flora, patrimonio, conocimiento, historia, etc.), imbuyéndolos de un mayor o menor valor en función de sus objetivos e intereses en el entramado territorial, seleccionando aquellos objetos que considera más relevantes para su estrategia y excluyendo a otros. Es cada sociedad y sus actores, la que activa sus componentes y los resignifica en el tiempo en función a nuevos contextos, nuevos usos y nuevas demandas. La dotación de estos activos entre los diferentes actores, así como su producción, gestión, explotación e intercambio va a influir directamente en la acción territorial. 


\section{El método de análisis}

El análisis de la acción territorial y los factores que actúan como freno o limitaciones a la misma fue realizado tomando un territorio del sur de la región pampeana. Dado el carácter cualitativo de la investigación y la administración de la prueba, la metodología de investigación se desarrollo en tres grandes etapas que permitieron consolidar paso a paso la información y el análisis inicial a través de miradas complementarias de diferentes actores. Las etapas de trabajo fueron las siguientes:

\section{Primera etapa de recopilación de información de base:}

En primer lugar se realizaron entrevistas en profundidad a 15 referentes claves de la acción pública, la acción privada y la acción colectiva, gran parte de ellos con responsabilidades en ámbitos políticos, institucionales o empresariales. Todas estas entrevistas tuvieron el mismo guion y fueron realizadas en forma individual (ver modelo de guión en anexo), las mismas tuvieron como objetivo identificar las representaciones que los actores tienen sobre el desarrollo del distrito, sobre las acciones más significativas puestas en marcha a nivel local y sobre las formas como estas acciones se llevan adelante.

Las variables claves sobre las que se trabajo en las entrevistas a los diferentes actores han sido las siguientes:

$\circ$

Toda la información recogida en las entrevistas se sistematizaron y codificaron en una hoja de cálculo lo cual permitió elaborar una tabla de frecuencias de todas las respuestas de todos los encuestados, considerando como elemento de clasificación primario el tipo de categoría de encuestado (acción pública, acción colectiva y acción privada). Con esta información dividida por tipo de actor se realizaron los cruces con las diferentes variables lo cual permitió analizar y caracterizar cada situación en particular, realizar análisis descriptivos e identificar y analizar los discursos de cada uno de los actores. El cuadro n01 presenta el modelo de tabla de doble entrada para el cruce de variables realizadas: 


\section{Cuadro $\mathrm{n}^{\circ} 2$}

Modelo de tabla de doble entrada para el cruce de variables de análisis

\begin{tabular}{|c|c|c|c|c|c|c|c|}
\hline \multirow{2}{*}{$\begin{array}{l}\text { Variables de } \\
\text { análisis }\end{array}$} & \multirow{2}{*}{$\begin{array}{l}\text { Resultantes de las entrevistas ya } \\
\text { codificadas }\end{array}$} & \multicolumn{2}{|c|}{$\begin{array}{c}\text { Actor } \\
\text { público }\end{array}$} & \multicolumn{2}{|c|}{$\begin{array}{c}\text { Actor } \\
\text { privado }\end{array}$} & \multicolumn{2}{|c|}{$\begin{array}{c}\text { Actor } \\
\text { colectivo }\end{array}$} \\
\hline & & No & $\%$ & No & $\%$ & $\mathrm{~N}^{\circ}$ & $\%$ \\
\hline \multirow{5}{*}{ Debilidades } & $x$ & & & & & & \\
\hline & $x$ & & & & & & \\
\hline & $x$ & & & & & & \\
\hline & $x$ & & & & & & \\
\hline & $x$ & & & & & & \\
\hline \multirow{5}{*}{ Fortalezas } & $x$ & & & & & & \\
\hline & $x$ & & & & & & \\
\hline & $x$ & & & & & & \\
\hline & $x$ & & & & & & \\
\hline & $x$ & & & & & & \\
\hline \multirow{3}{*}{$\begin{array}{l}\text { Escenario de } \\
\text { futuro }\end{array}$} & Modernización & & & & & & \\
\hline & Alternativo & & & & & & \\
\hline & Tendencial & & & & & & \\
\hline \multirow{6}{*}{$\begin{array}{l}\text { Acciones en } \\
\text { marcha }\end{array}$} & Acciones económicas y productivas (AEP) & & & & & & \\
\hline & Acciones socioculturales (ASC) & & & & & & \\
\hline & Acciones político institucionales (API) & & & & & & \\
\hline & Acciones ambientales (AA) & & & & & & \\
\hline & Acciones de infraestructuras (AI) & & & & & & \\
\hline & Acciones de ordenamiento territorial (AOT) & & & & & & \\
\hline \multirow{4}{*}{$\begin{array}{l}\text { Recursos movi- } \\
\text { lizados }\end{array}$} & Rec de gestión política & & & & & & \\
\hline & Rec Económicos & & & & & & \\
\hline & Rec Humanos & & & & & & \\
\hline & Rec confianza & & & & & & \\
\hline \multirow{5}{*}{ Resultados } & $x$ & & & & & & \\
\hline & $x$ & & & & & & \\
\hline & $x$ & & & & & & \\
\hline & $x$ & & & & & & \\
\hline & $x$ & & & & & & \\
\hline \multirow{6}{*}{$\begin{array}{l}\text { Limitantes a la } \\
\text { acción }\end{array}$} & $x$ & & & & & & \\
\hline & $x$ & & & & & & \\
\hline & $x$ & & & & & & \\
\hline & $x$ & & & & & & \\
\hline & $x$ & & & & & & \\
\hline & $x$ & & & & & & \\
\hline
\end{tabular}




\section{Segunda etapa de validación de información:}

En un segundo momento, y para poder tener más fortaleza en la validación de la información recopilada y analizada, se realizaron 10 entrevistas más a ciudadanos sin participación o responsabilidades directas en el sector público, en organizaciones sociales ni en el sector privado, la mayoría de ellos empleados en diferentes actividades, en comercios o industrias locales y maestros. El objetivo de estas entrevistas complementarias fue cotejar y validar los resultados de la primera serie de entrevistas.

\section{Tercera etapa de validación definitiva y enriquecimiento de conclusiones:}

En un tercer momento, y con el objetivo de continuar fortaleciendo la administración de la prueba, se realizó un breve informe el cual se distribuyó a 8 referentes de la comunidad que no participaron en la ronda de entrevistas previas, con la presencia de todos ellos se realizó un focus group para debatir los resultados de esta investigación. Este trabajo grupal permitió validar la hipótesis de trabajo y enriquecer el análisis y las conclusiones a las cuales se arribaron.

\section{El escenario de análisis de la acción territorial}

Cualquier acción territorial se produce dentro de un espacio de interacción en donde se construye un vínculo social y se intercambian recursos (Knoepfel et al., 2007; Subirats, 2008). Estos espacios pueden tener diferentes dimensiones, pero son ante todo los espacios de acción cotidiana de los actores, esto puede ser un paraje rural, un pueblo y su área de influencia, una pequeña microrregión, una provincia, etc. Lo que define el territorio de acción no son las fronteras o los límites políticos administrativos, sino el poder de actuación o la legitimidad que los actores tienen sobre un territorio. Estos espacios se encuentran dentro de un contexto espacial estructurante $o$ ámbito de referencia (territorio nacional o provincial) que es el que define ciertas condiciones a las cuales se sujetan los actores.

En este caso, el contexto espacial lo constituye la Región Pampeana, un ámbito territorial constituido por las Provincias de Entre Ríos, Santa Fe, Córdoba, La Pampa y Buenos Aires, con una superficie de casi 4 millones de $\mathrm{km}^{2}$ y una población de más de 21 millones de habitantes. Esta región goza de una posición geográfica excepcional ya que limita con el mayor número del resto de las regiones del país lo cual le otorga una función geoestratégica que aumenta su importancia a nivel nacional. Desde finales del siglo XIX, el clima templado y húmedo, la densa red hidrográfica y los suelos fértiles de la región favorecieron el desarrollo de la actividad agraria (cereales y oleaginosas) y ganadera (vacuna especialmente), que constituye el principal factor de organización del espacio pampeano, bajo un modelo netamente agroindustrial - exportador (Sili, 2015). La región se ha consolidado como productora de bienes primarios orientados a la exportación, con baja densidad de población en el campo, con una mayor concentración en los pueblos y especialmente en pequeñas y medianas ciudades donde se concentra el sector comercial y de servicios de apoyo al sector agroindustrial. Si bien se trata de una región donde coexistan territorios más o menos dinámicos, es una región muy estructurada y estable donde las principales transformaciones se vinculan mayormente al cambio tecnológico en el sector productivo, a las 
condiciones del mercado internacional y claramente, a la capacidad de innovación y dinamismo de sus actores locales (Sili, 2015).

Dentro de este contexto territorial se localiza el Distrito de Saavedra, escenario de análisis de la acción territorial (figura 1). El mismo se ubica en el sudoeste de la provincia de Buenos Aires, 100 kilómetros al norte de la ciudad de Bahía Blanca. Este Distrito se caracteriza desde el punto de vista ambiental por tener suelos fértiles y un relieve llano, con un pequeño sector de sierras hacia el este. El clima es templado y las precipitaciones de unos $800 \mathrm{~mm}$ por año, con una mayor presencia de lluvias en el verano. La cubierta natural herbácea típica de la región pampeana, ha sido reemplazada por cultivos de verano y de invierno, especialmente de trigo, constituyendo una de las áreas de referencia para la producción agrícola en Argentina. El principal asentamiento humano es la localidad de Pigüé, cabecera del Distrito, con 15.000 habitantes y en constante crecimiento debido a las migraciones provenientes del campo, del norte argentino, de países limítrofes y, muy especialmente, de Buenos Aires y Bahía Blanca, en busca de una mejor calidad de vida. En el Distrito se encuentran otros asentamientos que cumplen funciones de centros de servicio para el área rural: Arroyo Corto (500 habitantes), Espartillar (1.200), Saavedra (2.400) y Goyena (900). La población de estos pueblos se mantiene estable o aumenta levemente, gracias al crecimiento vegetativo y a las personas que migran del campo. La población dispersa, que habita en las explotaciones agropecuarias, alcanza los 5.000 habitantes, la misma ha disminuido sistemáticamente en las últimas décadas debido al cambio en los sistemas de producción y la búsqueda de una mejor calidad de vida en los pueblos.

Figura No1

Localización del área de estudio

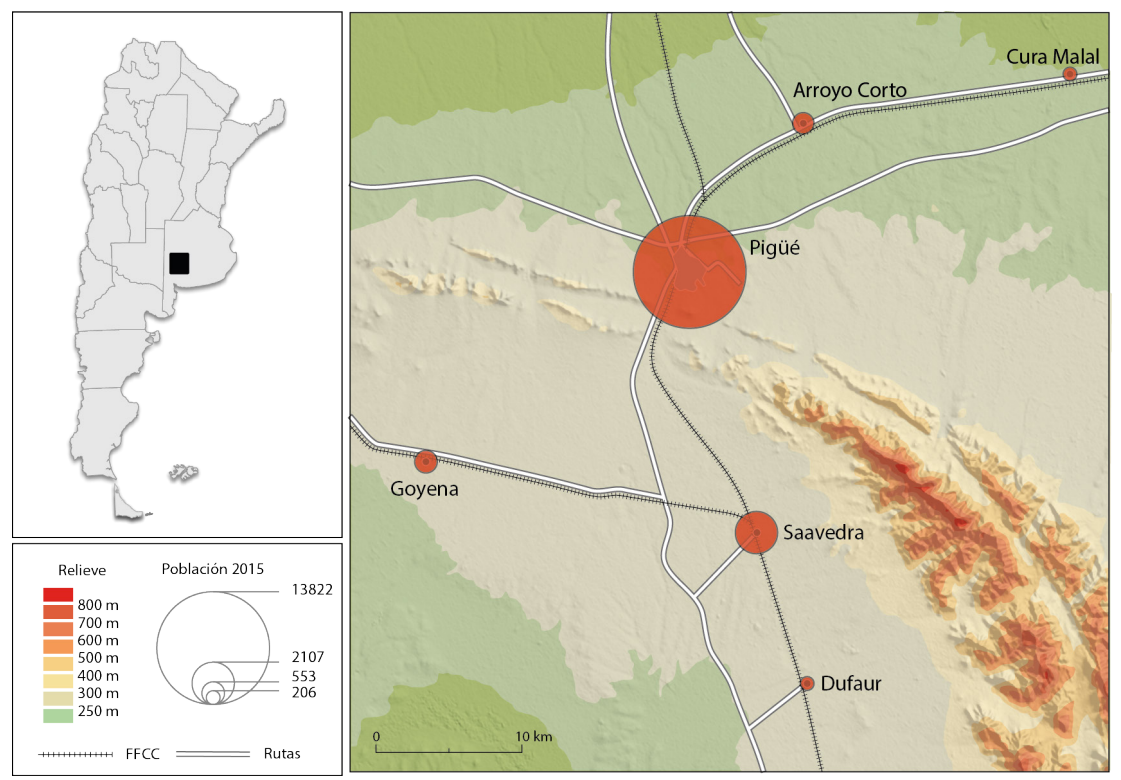

Fuente: elaboración personal 
El nivel educativo de la población es elevado: la mayor parte de la población tiene el nivel secundario completo, y hay una gran proporción con estudios terciarios y universitarios. En líneas generales, la calidad de vida en los pueblos y ciudades es muy elevada, con un muy bajo nivel de NBI y de pobreza.

La actividad económica predominante es la agricultura -trigo y cebada- y la ganadería. La agricultura familiar de talla pequeña o mediana (entre 100 y 500 hectáreas), estructuró históricamente el funcionamiento de la agricultura regional, en estrecha relación con el sistema cooperativo. En las últimas décadas, la producción agropecuaria ha vivido un doble proceso de transformación. Por un lado, cambios tecnológicos y económicos han impulsado un aumento de escala en las unidades productivas, los campos más pequeños no tienen la escala suficiente para poder sostener su actividad lo que impulsa la concentración de la tierra y el aumento de las explotaciones agropecuarias, las cuales ahora son gestionadas no solo por los productores agropecuarios tradicionales más capitalizados, sino también por nuevos propietarios (muchas veces no locales), contratistas y arrendatarios con mayor capital. Son estos actores más capitalizados los que pueden incorporar las nuevas tecnologías y los nuevos modelos de gestión. Asociado a ello también hay un cambio hacia la producción de cultivos de verano (soja y girasol), debido a su mayor rentabilidad, aunque dicha actividad sea más riesgosa y menos sustentable en esta área de fuerte ciclicidad climática. La presencia de servicios especializados de agronomía y veterinaria de alta calidad, está asociada a los cambios productivos mencionados. En ese sentido, esta zona vive el mismo proceso de transformación hacia modelos productivos de mayor tamaño e incorporación de tecnología que se visualiza en toda la región pampeana.

Las industrias, localizadas en los pueblos de mayor tamaño, transforman bienes primarios (molinos harineros, empresas lácteas, alimentos balanceados, etc.) o pertenecen al complejo textil conformado por pequeños o medianos talleres de confección de ropa o calzado deportivo, y que emergieron en décadas anteriores como proveedoras de grandes fábricas textiles de nivel nacional e internacional. El sector terciario es importante, con numerosos servicios especializados para la producción agropecuaria y agroindustrial, comercios, servicios personales y otros servicios de mediana complejidad. La presencia de instalaciones militares y carcelarias genera empleos estables y una demanda de bienes y servicios importante en la zona que permite mantener la estructura comercial local. En líneas generales, el sistema productivo local es sumamente estable, con mediano nivel tecnológico, con vocación a la innovación y a la integración entre sectores, con un importante peso de los servicios.

Desde el punto de vista ambiental, si bien no se manifiestan grandes problemas, existen conflictos por el uso del suelo y el deterioro paisajístico, producto de un crecimiento desordenado de las localidades, especialmente de Pigüé, así como por el uso de agroquímicos en los campos.

Estas características generales permiten tipificar a este Distrito como una zona típica de la región pampeana, con una elevada calidad de vida, pero con una dinámica estable de desarrollo económico productivo.

Sin embargo, desde la perspectiva de la acción territorial interesa entender no solo las condiciones estructurales del territorio, sino también la mirada que los actores locales tienen sobre 
el mismo y sobre su futuro, pues es a partir de dichas miradas que se movilizan y construyen las acciones territoriales.

Figura $\mathrm{N}^{\circ} 2$

Principales debilidades del Distrito de Saavedra según la opinión de los actores locales

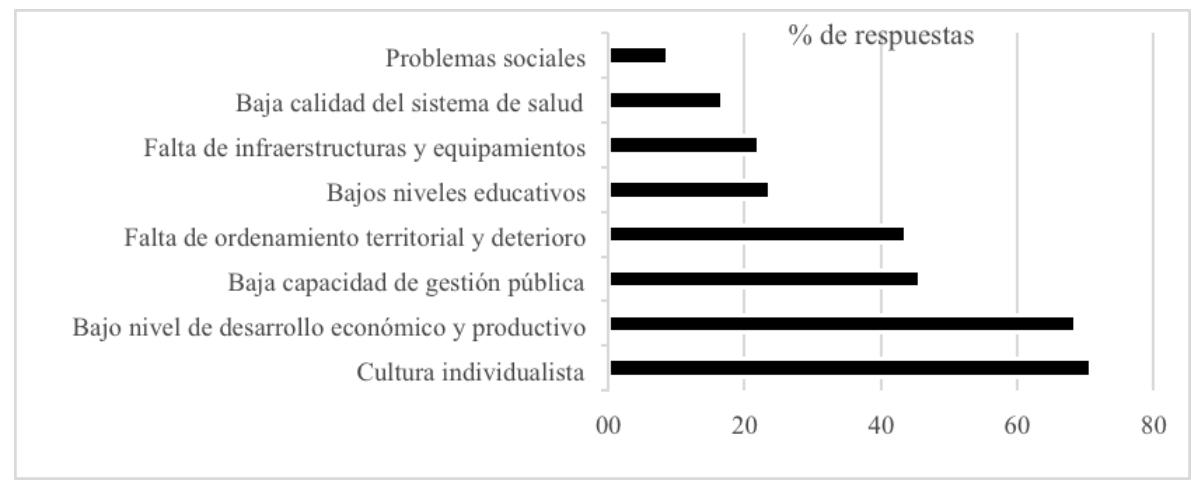

Fuente: Elaboración personal en base a encuestas locales

A la vista de los actores locales las principales debilidades de este territorio son, en primer lugar una cultura individualista de su población (falta de compromiso con el territorio, actitudes oportunistas y carencia de una visión de largo plazo) y el bajo nivel de desarrollo económico productivo (baja actividad, bajos salarios, deslocalización de la renta en otras ciudades cercanas). Esta debilidad es claramente percibida y planteada por los actores de la acción colectiva, quienes además manifiestan una gran preocupación dada las dificultades que existen para potenciar y desarrollar aún más la vida colectiva. En relación al bajo nivel de desarrollo económico y del empleo, es el sector público el que manifiesta mayor preocupación, dado que los problemas de empleo generalmente son atendidos a través de subsidios o de la atención social por parte del municipio.

En segundo lugar aparecen dos debilidades que tienen relación directa a la acción pública, la primera es la percepción generalizada de baja capacidad de la gestión pública y la falta de ordenamiento territorial y de deterioro ambiental, problemática que debiera ser atendida desde una mejor gestión territorial. Ya en tercer lugar, pero con mucha menor importancia, aparecen otros problemas como el bajo nivel educativo, la baja calidad de sistemas de salud y los crecientes problemas sociales, además de falta de infraestructuras y equipamientos.

Por otro lado, las principales fortalezas planteadas por los actores locales son en primer lugar el constituir un Distrito tranquilo, con pocos hechos de violencia, donde se puede vivir seguro en relación a otros lugares del país y especialmente las grandes ciudades. Esta percepción es muy fuerte en los actores de la acción colectiva y privada. En segundo lugar aparecen las condiciones geográficas de clima, relieve, conectividad y condiciones ambientales en general como fortalezas del territorio, especialmente para los actores de la acción pública. La tercera fortaleza es la presencia de una comunidad solidaria, lo cual se expresa en la activa vida colectiva (comisiones, organizaciones de la sociedad civil, etc.), la cual es vista como la responsable de la dinamiza- 
ción de la vida local (esto podría aparecer como una contradicción pues en las debilidades del territorio aparece como importante la presencia de una cultura individualista, pero cabe aclarar que esta definición está condicionada por los actores de la acción colectiva quienes demandan más participación de la comunidad para poder sostener la densa vida colectiva local). En cuarto lugar, como una fortaleza importante aparece el proceso de renacimiento rural, o la vuelta de los jóvenes al territorio. Este retorno de los jóvenes es percibido especialmente por los actores de la vida colectiva, quienes ven además en este retorno una fuerte posibilidad de recambio en las organizaciones de la vida social local. Finalmente la percepción generalizada para todos los actores que se trata de un Distrito con una población con una fuerte tradición de dedicación al trabajo.

Figura $\mathrm{N}^{\circ} 3$

Principales fortalezas del Distrito de Saavedra según la opinión de los actores locales

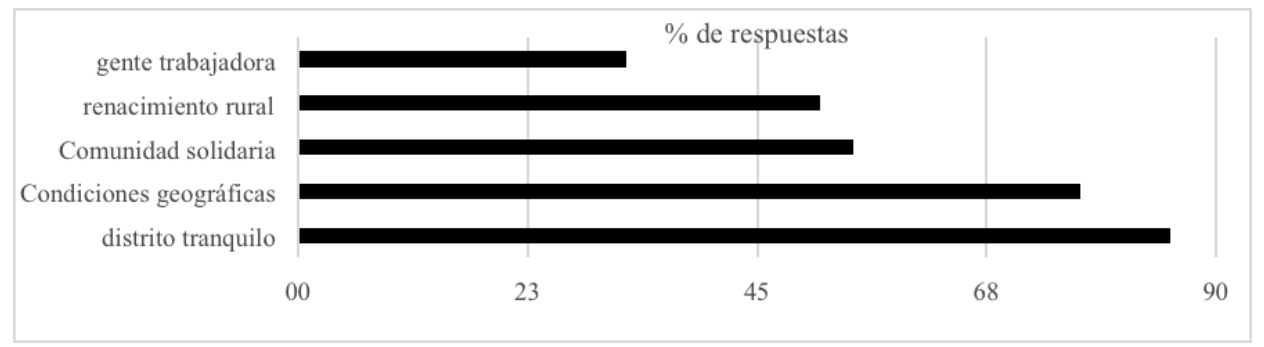

Fuente: Elaboración personal en base a encuestas locales

\section{Deseos de futuro. Contradicciones en la vida cotidiana}

Frente a este escenario territorial y a las problemáticas y fortalezas planteadas a nivel local, interesa entender cual es futuro que los actores pretenden para su territorio, cuál es el deseo de futuro de la sociedad local y como es el territorio que los actores en mayor o menor medida han diseñado en forma consciente en sus mentes aunque esto no se explicite en términos de discursos y políticas. Es importante entender estos deseos de futuro pues la definición del proyecto de futuro del territorio (Vanier, 2015) es clave para la estructuración de la acción y de políticas, ya que la imagen de futuro puede favorecer la convergencia y concertación de múltiples actores en torno a un ideario del territorio (Appadurai, 2015). Así los objetivos y escenarios deseados de futuro permiten construir utopías capaces de movilizar y concertar diferentes actores de la sociedad favoreciendo la constitución de un proyecto territorial a partir del cual la solidaridad y el juego de competencias se ordenan. En otras palabras, estos deseos de futuro constituyen la chispa que enciende las acciones constructoras del territorio.

Así, la definición de un proyecto de futuro con sus objetivos actúa como marco de regulación de las energías y los conflictos sociales, en función de un proyecto colectivo. Este proyecto de futuro aparece entonces como el faro que orienta y hacia el cual se dirigen las acciones de una sociedad, actúa como utopía movilizadora de la sociedad pues lo que no es todavía actúa sobre la realidad actual. Así, el territorio se define y gestiona desde el presente a partir de un proyecto 
de futuro, poniendo en valor el legado histórico para adecuarlo a las exigencias actuales (François et al. 2006; Lajarge, 2011). Desde el punto de vista analítico, y también desde una perspectiva de planificación y desarrollo, interesa entonces entender la tensión que se produce entre el presente y los objetivos y escenarios deseados para el futuro, ya sean implícitos o explícitos a través del discurso, pues esta tensión es la que promueve la acción territorial, materia prima de cualquier proceso de ordenamiento y desarrollo territorial.

Tres escenarios de futuro claramente diferenciados han podido ser analizados a través de esta investigación.

En primer lugar hay un deseo de futuro que se impregna en la vida cotidiana y responde claramente al ideario y el discurso del crecimiento, la modernización y el progreso. Este deseo (crecimiento, modernización y progreso) ilumina el pensamiento de los actores locales y opera como telón de fondo de las múltiples acciones locales, y se encarna en los discursos políticos de corto plazo. Cuatro imágenes aparecen como modelo deseado de futuro:

- El crecimiento de la población, lo cual hipotéticamente aseguraría una mayor cantidad de consumidores y movimiento comercial.

- La presencia de fábricas con obreros, grandes estructuras edilicias, y salarios garantizados a fin de mes.

- La pavimentación de los pueblos y las ciudades

- La iluminación potente de calles, comercios, plazas y vías de acceso

Este deseo de futuro, que se acerca claramente a una imagen estereotipada de progreso y modernidad urbana, es mayoritario en la población local, y muy especialmente en los sectores sociales de menores ingresos y menor movilidad social y espacial. Este deseo es utilizado en los discursos políticos, como mecanismo de generar mayor adhesión política. Así muchas veces el discurso político electoral, plantea: "Hacer es CRECER", "EI CRECIMIENTO y el PROGRESO de la Comunidad", en todos ellos la palabra crecimiento aparece como la llave que abre las puertas hacia un futuro mejor, tal como lo expresa un dirigente local:

“Hacia el futuro, ser una ciudad grande e industrial, con mucha gente, una gran ciudad y no un pequeño pueblo"

Esta frase no solo encierra la aceptación plena de la ciudad como sinónimo de modernidad y progreso, sino también delimita a lo rural (el pueblo) como el lugar de la tradición, de lo no deseado de lo cual hay que escapar o superar.

En segundo lugar aparece un deseo de futuro completamente contrastado con el anterior. Ya no es el crecimiento, la modernidad y el progreso el que estructura el discurso y el deseo del futuro, sino todo lo contrario, es la imagen recuperada de lo rural, un futuro slow city, slow food, de reencuentro y cercanía con una naturaleza sana, sin utilización de agroquímicos, de relaciones comunitarias, con más tiempo libre y menos consumo. Este deseo de futuro encarna las demandas de los neorurales y nuevos habitantes de las zonas rurales que gozan generalmente de otras condiciones de movilidad y contacto con el mundo, lo cual les permite satisfacer sus demandas de consumo y actividades culturales en otros lugares, en abierta contradicción con los habitantes 
de siempre de la zona quienes visualizan este modelo de futuro como contrario al crecimiento y el progreso. Tal como lo expresa un nuevo habitante del lugar:

"Yo quisiera que este pueblo se mantenga así, con calles de tierras, con los chicos jugando y andando en bicicleta por la calle, que nos conozcamos todos, no quiero que crezca, sólo que mejoren algunos servicios"

En tercer lugar aparece otra imagen de futuro, que no responde al deseo de los actores, sino que es resultado de la ocurrencia de procesos, y frente a los cuales los actores se sienten impotentes de cambiar, desviar o transformar. Es lo que claramente se puede reconocer como escenario tendencial y que se producirá a pesar de los actores locales y de sus iniciativas. Según la voz de los diferentes actores el futuro de Pigüé y del Distrito será:

“Una ciudad grande, con crecimiento, con más fábricas, sin desarrollo, sin alma colectiva, con deterioro ambiental"

"El Distrito seguirá igual que ahora, seguirá creciendo, con más fábricas, pero no desarrollándose"

"Un deterioro paulatino pero inexorable, a pesar de los adelantos tecnológicos, el aumento del consumo y la llegada de jóvenes al Distrito"

Este escenario tendencial que los actores visualizan hacia el futuro, se sintetiza en cuatro elementos claves: un sostenido crecimiento demográfico (especialmente en la ciudad cabecera), la aparición de nuevas fábricas ligadas a la agroindustria, fuerte degradación ambiental y menores niveles de desarrollo social y cultural. Esta imagen de escenario tendencial responde en parte al discurso de la modernización y el progreso demandado por gran parte de la población y fuertemente sostenido por las políticas públicas, pero también existe un reconocimiento que este escenario de futuro trae consigo elementos no deseados pero que con pesar se aceptan como el costo del progreso, la modernidad y el consumo. Este escenario tendencial constituye el estricto reconocimiento que el futuro no será lo que socialmente se pretende, sino que será el resultado de fuerzas y tendencias que los actores locales no pueden controlar.

La presencia de estos tres tipos de discursos o imaginarios de futuro, manifiestan dos hechos importantes, en primer lugar la diversidad local en términos culturales, de representaciones, imaginarios y deseos por parte de la población, y en segundo lugar, y tal como lo plantea nuestra hipótesis de trabajo manifiesta la inexistencia de un proyecto territorial de futuro compartido, es decir, se trata de un territorio y una sociedad local que no posee un sentido compartido y consensuado del devenir, del hacia donde se orienta y cual será su futuro. Un territorio huérfano de futuro cuyo devenir se construye en función del encuentro fortuito y no coordinados de las fuerzas de los múltiples actores. Esta situación ha sido claramente identificada a través del trabajo de campo, así, la totalidad de los actores y referentes entrevistados en las diferentes etapas de trabajo afirmaron que el Distrito no tiene definido y explicitado un proyecto o un escenario de futuro deseado hacia el cual se pueda avanzar o construir. Esta carencia de visión estratégica ha sido también observada por Diez quien resalta "Como hecho relevante, resulta importante resaltar que un número significativo de organizaciones consideró que no existían entidades con Visión estratégica en el partido.." (Diez et al. 2015, p. 284). 
Es esta orfandad o carencia de proyecto de futuro explícito y consensuado lo cual claramente limita el diseño de una política y una estrategia de desarrollo hacia el futuro, y por ende limita considerablemente la articulación y coordinación de acciones territoriales, tal como se analiza a continuación.

\section{Acciones para la construcción del territorio}

Dentro de este contexto de fragmentación y de falta de visión compartida de futuro, emergen acciones territoriales de diverso tipo, el análisis de estas acciones debe permitir responder a tres preguntas claves: ¿qué acciones ponen en marcha los diferentes actores para construir el territorio, teniendo en cuenta que no hay un claro escenario hacia donde avanzar?, ¿Cómo se ponen en marcha y se organizan dichas acciones?, y ¿qué resultados se generan?. Para poder responder a estas preguntas se realizo un relevamiento y análisis de las acciones, los actores involucrados en las mismas, la complejidad y la naturaleza de las acciones, y finalmente las opiniones y representaciones que los actores locales tienen sobre estas acciones y los actores que las llevan adelante. El cuadro $\mathrm{n}^{\circ} 2$ da cuenta de estas acciones

Cuadro $\mathrm{N}^{\circ} 2$

Acciones y actores involucrados en el Distrito de Saavedra

\begin{tabular}{|c|c|c|c|c|}
\hline \multirow{3}{*}{$\begin{array}{c}\text { Naturaleza de } \\
\text { las acciones }\end{array}$} & \multicolumn{4}{|c|}{ Tipos de actores involucrados } \\
\hline & \multicolumn{2}{|c|}{ Acción pública } & \multirow[b]{2}{*}{ Acción privada } & \multirow[b]{2}{*}{ Acción colectiva } \\
\hline & Local & $\begin{array}{c}\text { Provincial y } \\
\text { Nacional }\end{array}$ & & \\
\hline $\begin{array}{l}\text { Acciones } \\
\text { económicas } \\
\text { y productivas } \\
\text { (AEP) }\end{array}$ & \begin{tabular}{|ll} 
o & Capacitaciones \\
o & Promoción de \\
& Consorcio ex- \\
& portador de miel \\
o & Otorgamiento \\
& créditos PYmes \\
\end{tabular} & \begin{tabular}{|ll} 
o & Capacita- \\
& ciones \\
o & Apoyo \\
& financiero \\
& a Pymes
\end{tabular} & \begin{tabular}{|ll} 
- & Creación de em- \\
& presas Pymes \\
o & Apertura de loca- \\
& les comerciales \\
o & Consorcio expor- \\
& tación de miel
\end{tabular} & $\begin{array}{l}\text { o } \text { Atención de } \\
\text { la sanidad } \\
\text { animal }\end{array}$ \\
\hline $\begin{array}{l}\text { Acciones } \\
\text { socioculturales } \\
\text { (ASC) }\end{array}$ & $\begin{array}{ll}\text { o } & \text { Animación cul- } \\
& \text { tural } \\
\text { o } & \text { Organización de } \\
& \text { eventos sociales } \\
\text { y deportivos }\end{array}$ & $\begin{array}{ll}\text { o } & \text { Animación } \\
\text { cultural }\end{array}$ & 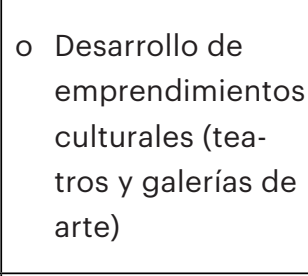 & \begin{tabular}{|ll} 
o & Animación \\
& cultural \\
o & Organización \\
& de eventos \\
& sociales y \\
& deportivos \\
\end{tabular} \\
\hline $\begin{array}{l}\text { Acciones } \\
\text { político } \\
\text { institucionales } \\
\text { (API) }\end{array}$ & $\begin{array}{ll}\text { o } & \text { Entrega de es- } \\
& \text { crituras } \\
\text { o } & \text { Centro de moni- } \\
& \text { toreo }\end{array}$ & \begin{tabular}{|ll} 
o & Entrega de \\
& escrituras \\
o & Capaci- \\
& taciones \\
INCAP
\end{tabular} & & \begin{tabular}{|l} 
o \\
Organización \\
de servicios \\
comunitarios \\
(prevención \\
de enferme- \\
dades, etc.)
\end{tabular} \\
\hline
\end{tabular}




\begin{tabular}{|c|c|c|c|c|}
\hline \multirow{3}{*}{$\begin{array}{l}\text { Naturaleza de } \\
\text { las acciones }\end{array}$} & \multicolumn{4}{|c|}{ Tipos de actores involucrados } \\
\hline & \multicolumn{2}{|c|}{ Acción pública } & \multirow[b]{2}{*}{ Acción privada } & \multirow[b]{2}{*}{ Acción colectiva } \\
\hline & Local & $\begin{array}{l}\text { Provincial y } \\
\text { Nacional }\end{array}$ & & \\
\hline $\begin{array}{l}\text { Acciones } \\
\text { ambientales } \\
\text { (AA) }\end{array}$ & & & & $\begin{array}{l}\text { o Protección } \\
\text { animal }\end{array}$ \\
\hline $\begin{array}{l}\text { Acciones de } \\
\text { infraestructuras } \\
\text { (Al) }\end{array}$ & $\begin{array}{ll}\text { o } & \text { lluminación de } \\
& \text { parques y plazas } \\
\text { o Playones depor- } \\
\text { tivos }\end{array}$ & \begin{tabular}{|ll} 
o & Pavimen- \\
& tación de \\
& zonas resi- \\
& denciales \\
o & Pavimen- \\
& tación de \\
& rutas \\
o & Centro de \\
& monitoreo \\
o & Punto \\
digital \\
o & Escuela \\
secundaria & secuna óptica
\end{tabular} & o Planta de silos & $\begin{array}{l}\text { O Dotación de } \\
\text { servicio de } \\
\text { telefonía e } \\
\text { internet }\end{array}$ \\
\hline $\begin{array}{l}\text { Acciones de } \\
\text { ordenamiento } \\
\text { territorial (AOT) }\end{array}$ & & & $\begin{array}{l}\text { O Creación de } \\
\text { loteos residencia- } \\
\text { les }\end{array}$ & \\
\hline $\begin{array}{l}\text { Principales } \\
\text { recursos } \\
\text { movilizados }\end{array}$ & $\begin{array}{l}\text { o Recursos econó- } \\
\text { micos, } \\
\text { o Recursos huma- } \\
\text { nos }\end{array}$ & \begin{tabular}{|ll} 
o & Recursos \\
& económi- \\
& cos \\
o & Recursos \\
& normati- \\
& vos
\end{tabular} & $\begin{array}{l}\text { o Recursos econó- } \\
\text { micos }\end{array}$ & $\begin{array}{ll}\text { O } & \text { Recursos } \\
\text { humanos } \\
\text { o } \\
\text { Recursos de } \\
\text { confianza } \\
\text { O Recursos } \\
\text { relacionales }\end{array}$ \\
\hline
\end{tabular}

Fuente: Elaboración personal en base a encuestas y entrevistas

La acción pública local (municipio) concentra sus acciones en el mantenimiento de servicios municipales (mantenimiento de calles y caminos rurales, servicios administrativos, hospital municipal, etc.), la animación cultural, social y deportiva, en algunas acciones de promoción del empleo y la creación de infraestructuras menores como mejora de plazas y parques. Para la puesta en marcha de estas acciones, el sector público recurre a la utilización de recursos económicos y recursos humanos, tanto municipales como de cooperativas de trabajo, bajo una lógica de corto plazo dada la fuerte periodicidad de elecciones locales y por ende la urgencia por parte del poder político de generar eventos rápidamente aunque de bajo impacto territorial. Esta lógica de corto plazo es la que en definitiva incuba la realización de eventos sociales y culturales (encuentros, festivales, etc.) o de creación de infraestructuras con fuerte capacidad de marketing político, 
antes que procesos estructurales de animación para la generación de empleo, de ordenamiento territorial, de infraestructuras de mayor impacto territorial. Parte de estas acciones responden claramente a un sistema de representaciones que responden al modelo de modernización y crecimiento, razón por la cual las principales acciones reflejen claramente este discurso (iluminación, pavimento por ejemplo). El único elemento propio de este discurso de la modernización y el crecimiento, que es la instalación de una fábrica para generar empleo local, no es una acción posible de concretar, no sólo por las capacidades de gestión del municipio, sino por las condiciones estructurales de la economía y la gran distancia del Distrito de los centros más dinámicos y atractivos para las inversiones industriales como las deseadas aquí.

La acción pública de nivel provincial y nacional por otro lado centran sus acciones en la creación de infraestructuras más estructurantes como son la pavimentación de rutas y de calles urbanas, y en otras iniciativas menores de promoción del desarrollo, para ello moviliza recursos económicos y normativos (que constituyen las bases legales y reglamentarias de derecho constitucional, civil y administrativo, que organizan la vinculación entre el gobierno provincial y el municipal).

La opinión generalizada a nivel local es que la acción pública claramente representada por el municipio local, es de muy baja calidad, sin visión de largo plazo, muy poco significativa y que sólo se concentra en generar eventos sociales y culturales o infraestructuras menores, con nulo o bajo impacto en la mejora de las condiciones del territorio, situación que se condice con la necesidad de generar una imagen positiva de corto plazo, más que como un actor transformador del territorio. Esta percepción ubica al Municipio como un actor proveedor de recursos económicos o humanos, que son los recursos que el resto de los actores visualizan que este puede puede aportar. No se piensa en el sector público como un operador o líder capaz de generar dinámicas de desarrollo sostenibles, sino como un actor que genera acciones visibles de muy bajo impacto estructural, pero que pueden ser rápidamente exhibidas como resultados de la gestión política. Tal como lo expresan diferentes actores locales:

"Hay una clara ausencia del sector público en ciertos aspectos y es ahí donde intervienen las distintas comisiones locales para cubrir esas falencias"

"El sector público piensa a corto plazo, no hay políticas a futuro"

La acción privada por otro lado esta centrada en el mantenimiento de sus actividades productivas con mayor o menor suerte dependiendo de las condiciones macroeconómicas, de las condiciones del clima y los mercados, en la creación de pequeños emprendimientos y empresas, y en locales comerciales en los pueblos, movilizando para ello principalmente recursos económicos. La opinión de los múltiples actores locales sobre la acción privada es que la misma esta muy estratificada socialmente, entre los sectores sociales y económicos de mayores ingresos y los de menores ingresos, pero que en líneas generales mantienen actitudes conservadoras y muy individualistas y sin compromiso para construir un proceso de mejora del territorio. Las críticas sobre la actuación de la acción privada provienen mayormente del sector público, quienes ven a los actores privados como los responsables de la falta de empleo y del bajo nivel de desarrollo económico local, tal como lo afirman referentes del sector público:

"En el sector privado hay mucho individualismo, solo buscan su beneficio propio". 
La acción privada "Es negativa y pesimista, no generan clima de negocios y de proyectos"

Finalmente la acción colectiva por otro lado tiene una fuerte participación y actividad en torno a la animación cultural (teatros, centros de exposición cultural, intercambios culturales, etc.), la organización de eventos sociales (cenas, fiestas comunitarias, etc.), la animación deportiva (varios clubes que organizan diversas y numerosas actividades y campeonatos deportivos) y actividades comunitarias vinculadas a la salud y la sanidad. Los recursos privilegiados en la acción colectiva son recursos humanos, de confianza y relacionales (redes de colaboración), recursos que se deben construir en el tiempo, de allí que la rítmica temporal del sector asociativo local es muy diferente al resto de los actores, se piensa en términos de mediano y largo plazo. Las reflexiones de los referentes de la acción colectiva traduce una preocupación por la sostenibilidad y la durabilidad de la vida comunitaria y de las organizaciones, antes que la búsqueda de competitividad o de poder político. Las representaciones que estas organizaciones construyen sobre el futuro son bastante heterogéneas, aunque claramente predomina un imaginario centrado sobre la vida comunitaria, la identidad local y la necesidad de mejorar la calidad de vida, por encima de la búsqueda del crecimiento local. La opinión local sobre la acción colectiva es que esta se encuentra presente en todos los aspectos de la vida local, que es muy densa y que son las que hacen vivir al Distrito y a sus pueblos, a pesar que también se observa una fuerte desarticulación y conflictos entre ellas en busca de recursos y de un mayor protagonismo simbólico local. Tal como lo expresan actores locales:

"Las Instituciones funcionan bien, son dinámicas, igual hay conflictos y competencias entre ellas. Las intenciones son muy buenas"

"Hay Organizaciones que trabajan muy bien (Clubes, Cooperadoras, etc.). Llevan adelante acciones comunitarias. Pero se cansan de tanto hacer"

"Las instituciones son las que hacen vivir al pueblo"

La puesta en marcha de las acciones implica la existencia de un sistema de acción local desde donde se diseñan y ejecutan las mismas, es un sistema en donde interactúan múltiples actores, en donde cada uno de ellos se moviliza según sus intereses o sus redes de cooperación y solidaridad, pretendiendo influir, bloquear o activar estrategias de acción a partir de los distintos medios que se encuentran a su disposición. Este campo constituye entonces una arena (Giddens, 1984), un tejido de interacciones en el que concurren diferentes tomas de posición de los múltiples actores involucrados a través de la acción pública, la acción colectiva y la acción privada, con implicancias en el entramado decisional (Subra, 2008; Faure, 2008; Masson Vincent, 2008).

A mayor complejidad de las iniciativas y las acciones, mayor complejidad del modelo de organización y gobernanza seguido por los actores para llevar adelante las acciones que construyen territorio. En el caso del distrito de Saavedra este sistema o modelo de organización para la construcción de la acción territorial es básicamente combinado, ya que implica una complementariedad entre una lógica horizontal en la cual coexisten numerosas organizaciones con similares niveles jerárquicos (clubes, comisiones, asociaciones) que interactúan entre sí, y una lógica jerárquica de relación entre el Municipio y el Gobierno provincial que también plantea y ejecuta acciones a nivel local, la figura da cuenta del modelo de vinculación entre los actores dentro de la gobernanza local del Distrito de Saavedra. 
La figura $n^{\circ} 4$ muestra el tipo de acción predominante (pública, privada y colectiva) y el tipo de proyectos que llevan adelante, además de los tipos de vínculos que construyen los actores para la construcción de sus acciones. Estos vínculos son mayormente débiles y oportunistas a nivel local, la mayor parte de las veces basadas en normas informales, claramente este tipo de vínculos se establece entre el sector público con el sector privado y con la acción colectiva, y entre la acción colectiva y la acción privada. Pero también pueden reconocerse vínculos fuertes e institucionalizados entre la acción pública provincial y local, dada las relaciones jerárquicas que se encuentran formalizadas jurídicamente e institucionalizadas en estructuras reglamentarias.

Figura $\mathrm{N}^{\circ} 4$

Organización de la acción territorial en el Distrito de Saavedra

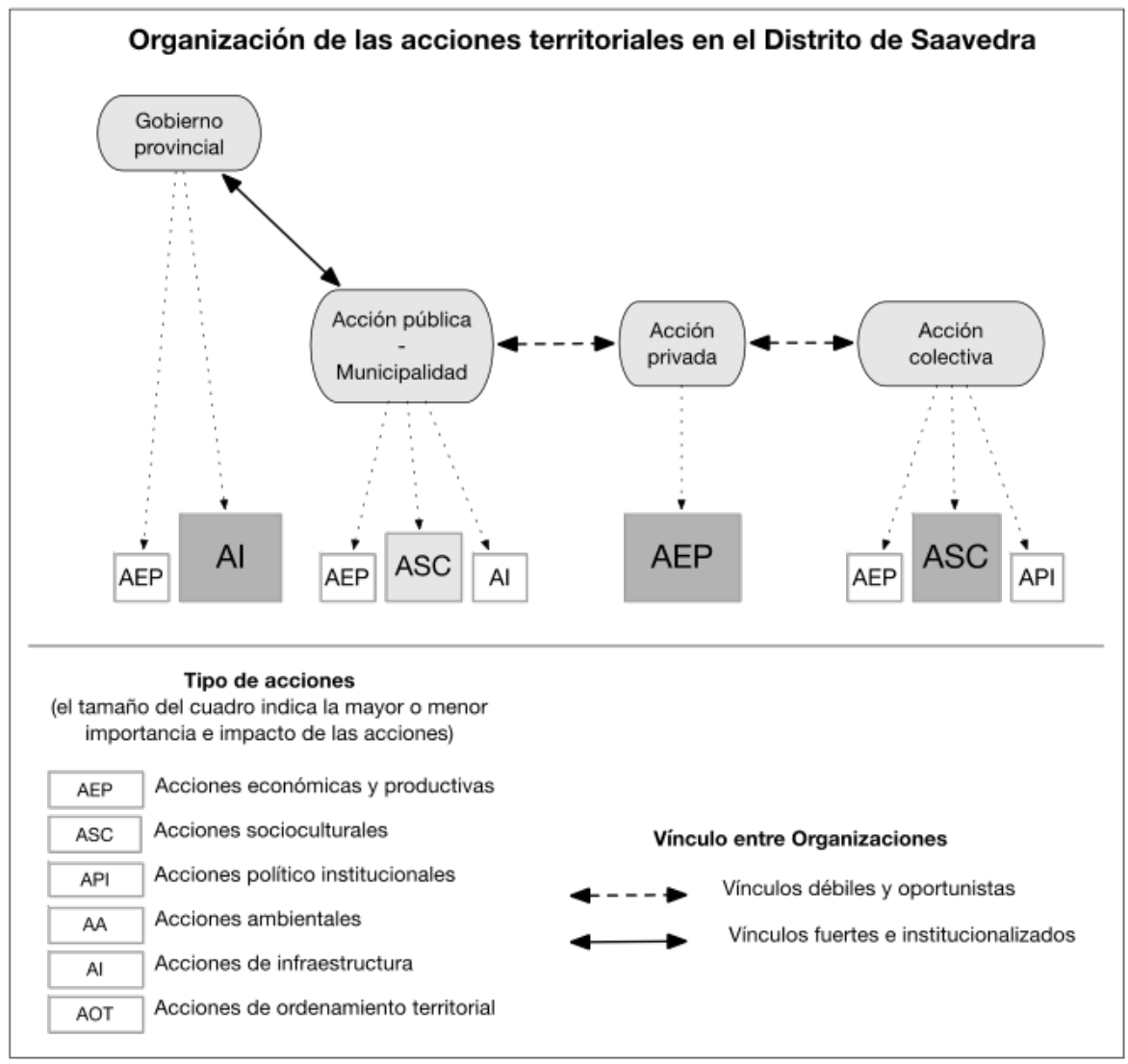

Fuente: elaboración personal

Teniendo en cuenta este modelo, interesa observar dos elementos directamente vinculado a la hipótesis de trabajo, la fuerte fragmentación de la acción territorial local y la falta de liderazgos claros capaz de generar procesos sinérgicos de desarrollo. 
Las relaciones horizontales dentro del sistema de organización local son muy fragmentadas, es decir, los vínculos entre la acción pública, la acción privada y la acción colectiva a nivel local son débiles y oportunistas, existe vinculación solo para casos muy específicos y de conveniencia para las organizaciones involucradas, pero una vez generada la acción o iniciativa que motivó la vinculación, este vínculo desaparece. Así por ejemplo, un club se vincula con otro para la realización de un evento, o con la Municipalidad para obtener recursos, pero no hay una estrategia permanente y estable de vinculación o creación de redes para sostener la cooperación y proyectos a futuro. Diez afirma "Se reconoció un total de 19 proyectos de colaboración en ejecución, que involucran a dos o más instituciones. Estos número puede ser considerado bajo si se lo compara con trabajos realizados para otras localidades de Argentina" (Diez, et al. p. 280). Tal como lo afirman varios entrevistados: "...cada uno lleva adelante sus proyectos solo, y hace lo que puede y cómo puede."

Esta lógica de organización fragmentaria de la acción territorial se vincula también a los marcos normativos que regulan el funcionamiento social. Así, en el caso específico del distrito de Saavedra las normas formales que reglamentan vínculos sólo se encuentran entre la acción pública de nivel provincial y de nivel local (municipalidad), pues existe un vínculo jerárquico y legal establecido por la constitución. (Knoepfel et al., 2007), claramente este vínculo esta supeditado también al juego político que establecen ambos niveles de gobierno. Los otros vínculos locales se organizan bajo reglas o normas informales, dado el conocimiento y el sistema de valores, símbolos y normas de comportamiento compartidos por todos los actores (Knight, 1992). Este sistema de normas, tanto formales como informales materializa las relaciones de poder entre los grupos sociales, facilitando o limitando las dinámicas de acción, en este sentido es importante reconocer que la carencia de reglamentaciones reconocidas y estables a nivel local que regulen el funcionamiento de los múltiples actores en torno a un proyecto territorial, son también causa (y consecuencia) de la dispersión y fragmentación de acciones, y por lo tanto de la pérdida de sentido y eficacia de las mismas.

Desde el punto de vista del liderazgo local y la centralidad de un actor sobre el resto de los actores, Diez afirma que "Las medidas de centralización de grafo de Freeman muestran valores que no son del todo significativos (36\% de entrada y salida, respectivamente) lo que evidencia la ausencia de una concentración importante de vínculos en un número muy reducido de actores" (Diez et al. p. 275). Es decir el intercambio de información y la construcción de proyectos compartidos es poco significativo, lo cual evidencia que no hay centralidad importante por parte de ningún actor local, es decir no hay liderazgos manifiestos.

Ahora bien, ¿Qué se logra a partir de las diferentes iniciativas de los actores involucrados?. Claramente un análisis pormenorizado permitiría cuantificar y describir la cantidad de eventos, los kms. de caminos pavimentados, las viviendas construidas, los planes y reglamentos de ordenamiento del uso del suelo, etc. Sin embargo, lo que interesa entender en materia de acción territorial no son esos datos en sí mismo, sino la percepción que los múltiples actores locales tienen sobre los resultados que el conjunto de las acciones han generado, pues es a partir de dichas percepciones y representaciones es que los actores locales construyen nuevas dinámicas y acciones, bajo una lógica de ciclo permanente de acciones que se retroalimentan en función del éxito o logros ya obtenidos con anterioridad. En otras palabras, y como lo plantea un entrevistado: "Si los proyectos vemos que funcionan seguimos apoyando, sino hacemos otra cosa" 
Figura N05

Resultados de la acción territorial desde la perspectiva de los actores locales

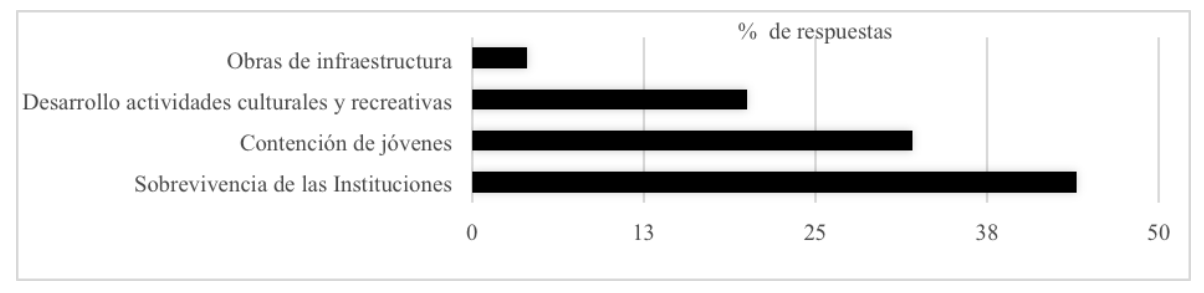

Fuente: Elaboración personal en base a entrevistas y encuestas

A partir del análisis del discurso de todos los actores locales se observa que el mayor logro generado a partir de las acciones locales son en primer lugar la sobrevivencia de las Instituciones, pues las actividades realizadas por las mismas les permiten generar ingresos que les asegura su continuidad en la vida local. En segundo lugar aparece la contención de los jóvenes de la comunidad como un resultado importante, esto se vincula al hecho que muchas de las actividades realizadas se vinculan al deporte o actividades para jóvenes que permitan que los mismos tengan un espacio en la comunidad y se fortalezcan los vínculos entre ellos, evitando así problemas de violencia, adicciones u otros problemas sociales. En tercer lugar el desarrollo de actividades culturales y recreativas aparece como un resultado importante en la comunidad, especialmente puestas en marcha por la acción colectiva y por el Municipio. Finalmente un resultado menor de las acciones locales es la creación de infraestructura por parte del Gobierno Provincial y el Municipio.

Claramente esta percepción que tienen el conjunto de los actores muestra una lógica de acción territorial claramente defensiva de procesos de crisis, las acciones puestas en marcha manifiestan la necesidad de resolver la vida de las Instituciones locales para que las mismas realicen las acciones que en el imaginario de la vida local, el gobierno municipal no realiza o coordina, y por otro lado contener a los jóvenes frente a posibles problemáticas sociales. No aparece desde la percepción de la población local acciones locales capaces de generar nuevas dinámicas económicas y productivas, generar empleos, organizar el territorio, mejorar las condiciones ambientales, consolidar la vida comunitaria, etc.

\section{Dinámica y limitantes a la acción territorial, la visión de los actores locales}

Claramente en el distrito de Saavedra se evidencian acciones de distinto tenor, orientadas idealmente a construir, organizar y mejorar las condiciones de vida y de producción en los mismos, bajo un inequívoco modelo de crecimiento y progreso, propio del paradigma de la modernización urbana, que no es el resultado de una visión compartida del futuro deseado por todos los actores locales, sino un modelo de futuro impuesto por la lógica política, asentado en un imaginario colectivo propuesto por gran parte de la sociedad. No obstante el resultado de las acciones en el territorio, de acuerdo a lo expresado por múltiples actores locales entrevistados, no ha dado 
los resultados esperados, al contrario, se viven procesos de deterioro territorial y ambiental (deterioro paisaje urbano, crecimiento no controlado, deterioro ambiental, etc.), con baja capacidad de innovación y de generación de empleos, y con un creciente deterioro social (aumento de problemas sociales, de inseguridad, etc.).

Tal como se planteó en la hipótesis de trabajo, la evidencia muestra que hay tres grandes factores que inhiben o limitan la generación de dinámicas más sinergéticas y virtuosas de desarrollo a nivel local, y que por lo tanto permiten o viabilizan este escenario de deterioro local, todos estos factores se condicionan y refuerzan mutuamente.

Figura $\mathrm{N}^{\circ} 6$

Factores claves limitantes del desarrollo local

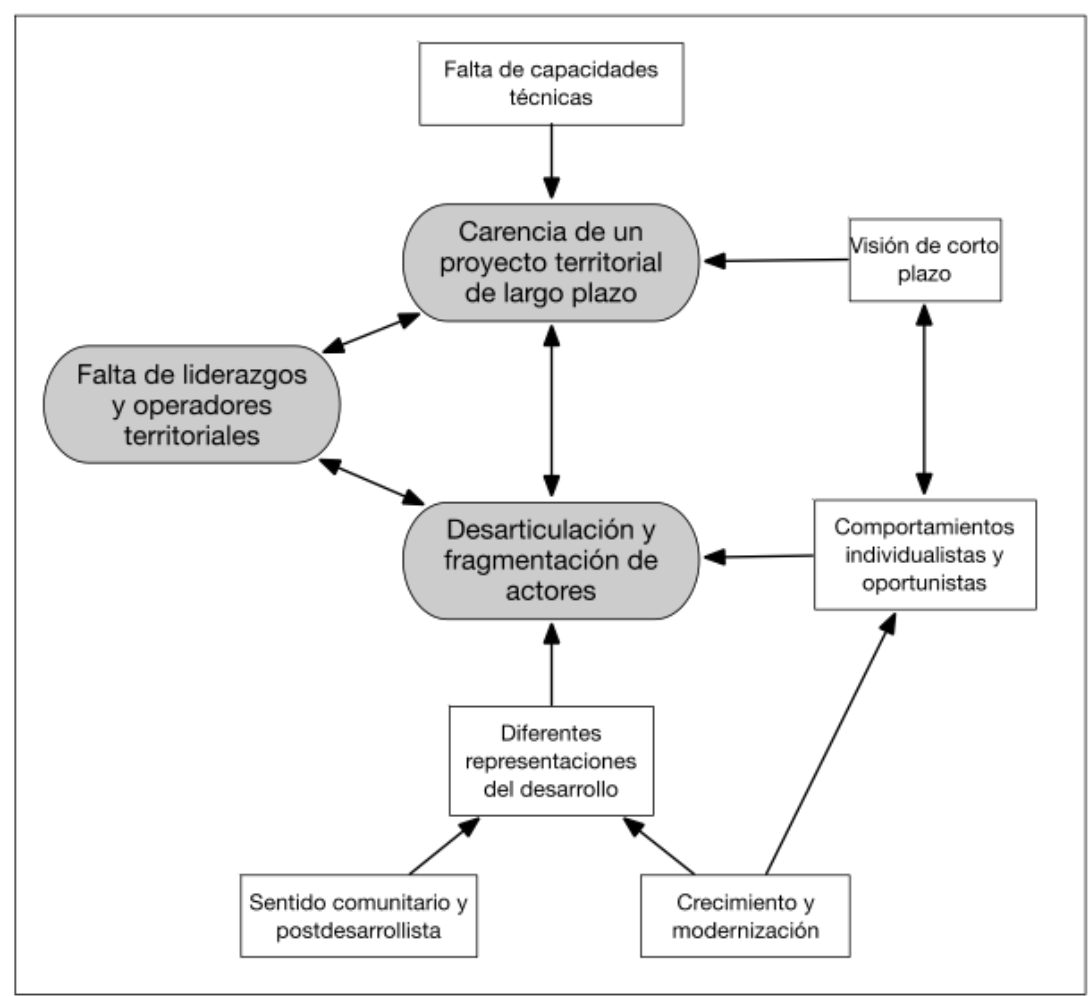

Fuente: Elaboración personal

El primero de estos factores es la carencia de un proyecto territorial de largo plazo, es decir una propuesta de futuro, consensuado y explicitado para el territorio. La falta de un proyecto compartido acelera y profundiza la fragmentación local y la incapacidad de valorizar las oportunidades que el territorio ofrece, empujando al territorio inexorablemente a un escenario tendencial que conjuga crecimiento, pero creciente degradación social, territorial y ambiental. Esta orfandad de proyecto territorial se debe a varias razones, en primer lugar porque predomina una visión de corto plazo en el sistema de acción local, especialmente desde la acción pública, dada la lógica 
política electoral que privilegia la construcción de poder en el corto plazo y la resolución de problemas coyunturales en lugar de pensar el futuro territorial, y en segundo lugar debido a la falta de capacidades técnicas y de gestión a nivel local capaz de colaborar en la construcción de un proyecto territorial. Esta falta de capacidades técnicas involucra a todos los actores pero más que nada a la acción pública, la cual no cuenta con cuadros técnicos necesarios para la planificación y la gestión del desarrollo territorial.

El segundo factor es la profunda desarticulación y fragmentación de los actores locales, producto de las diferentes representaciones que estos tienen sobre el desarrollo y sobre el territorio, y por otro lado por la preeminencia de comportamientos individualistas y oportunistas, claramente evidenciado por todos los entrevistados. Estos elementos se conjugan para que a nivel local se lleven adelante numerosas acciones por parte del sector público, colectivo y privado, pero estos no se articulan entre sí, generando lógicas de competencia y exclusión por encima de lógicas de cooperación.

El tercer factor es la falta de liderazgos locales. La falta de actores con capacidad de liderar, construir consenso y dinamizar la vida local es un factor evidente, lo cual no permite por un lado construir esta visión y proyecto de largo plazo y en función de ello coordinar la multiplicidad de iniciativas locales.

\section{Hallazgos y conclusiones}

La caracterización y el análisis del modelo de acción territorial del distrito de Saavedra permite rescatar cuatro grandes elementos o aprendizajes:

En primer lugar, el modelo de acción territorial que se ha construido en el distrito de Saavedra responde a una idea de futuro o escenario que responde al metamensaje de la modernidad, que entiende en su versión local que la presencia de fábricas, pavimento, luces, crecimiento urbano, son las condiciones básicas del progreso. Claramente este discurso e imaginario de la modernidad es parte de la sociedad local, pero se consolida y amplifica en el discurso de los referentes de todos los sectores políticos que operan bajo una lógica de corto plazo. Dado que este escenario o ideal de futuro no es posible de construir dadas las condiciones estructurantes y "objetivas" del territorio (baja densidad de población, bajo dinamismo económico comparado con las ciudades más grandes, carencia de infraestructuras, baja capacidad de gestión y ordenamiento territorial), esta idea de futuro resta como frustración, como un ideal que no se puede alcanzar, frustración que se traduce en exclamaciones tales como: "en este pueblo no pasa nada", "para progresar hay que irse a la ciudad", pues en definitiva la ciudad es el "lugar" donde la modernidad y el progreso se materializa y se hace realidad (Appadurai, 2015). Así, lo que se tiene es una contradicción, entre una imagen de la modernidad que busca el crecimiento y la instalación de fábricas como generadoras de empleo que garanticen ingresos, y unas condiciones objetivas del territorio en la cual no hay más empleo ni mejora de la calidad de vida. El futuro local es entonces paradojal, pues parte de ese futuro deseado se hace realidad con el crecimiento poblacional, pero él mismo viene acompañado con procesos de degradación social y ambiental contrarios a la idea de progreso. La consecuencia es que el futuro se presenta inexorable y lleno de conflictos y contradicciones, lo cual impele a los diferentes actores locales a centrar sus acciones en iniciativas de carácter 
paliativo o de defensa frente a una posible degradación de las condiciones de vida (trabajar para contener a los jóvenes, o para hacer sobrevivir a las Instituciones), pero no se generan iniciativas para construir un futuro deseado y consensuado por todos, más allá de la idea de la modernidad encarnada en más fábricas, más pavimentos y más población. Así, el futuro no se diseña, sino que se padece, pues es un futuro que evoca al crecimiento pero que advierte claramente y se resigna a la degradación. La experiencia local muestra entonces que para salir de esta trampa del trayectorismo occidental que conduce a un callejón sin salida de la modernidad + crecimiento es necesario construir un sentido de futuro posible, de un proyecto territorial convocante y plural, tarea técnica pero ante todo política que implica la construcción compartida de una visión de futuro, para lo cual es necesario liderazgos locales. La famosa expresión "No hay vientos favorables para aquel que no sabe a dónde va" cobra todo su sentido en este caso de análisis.

En segundo lugar y desde otra perspectiva también se puede afirmar que el territorio no tiene instrumentos ni métodos para construir un futuro deseado, pues los métodos empleados durante décadas en materia de planificación y gestión del desarrollo a nivel local ya no son eficaces. Las estrategias de actuación en solitario e individuales por la cual cada uno lleva adelante sus acciones, con fuerte competencia entre actores por la presencia simbólica en el territorio (los clubes o las instituciones por ejemplo), con estructuras burocráticas y administrativas jerárquicas (Municipio) y con acciones tradicionales (Municipio) no permiten construir dinámicas innovadoras de desarrollo. Se requieren nuevas capacidades técnicas, y nuevas lógicas y métodos de gestión que respeten las diferentes rítmicas culturales, representaciones e imaginarios colectivos, y sean capaces de gestionar y animar redes multiactorales y multiescalares en busca de consensos.

En tercer lugar queda claro que las formas de organización y las redes de los actores dentro del territorio es un tema clave para dar cuenta cómo las sociedades construyen su desarrollo. Sin embargo es importante reconocer que estas formas de organización han cambiado sustancialmente en el último medio siglo, pues de la posición jerárquica que supo cumplir el Estado (en este caso el Municipio y la Provincia) en la animación y organización territorial, se pasó a un poder relacional centrado en redes de agentes que intervienen en ámbitos plurisectoriales y en múltiples niveles escalares (regionales, nacionales e internacionales). Estas redes accionan diversos tejidos y organizaciones colectivas y privadas que tienen un peso cada vez mayor en la organización de los territorios tal como se evidencia en el Distrito de Saavedra con la participación de la acción colectiva como factor clave de sostenimiento del territorio (Moncayo Jiménez, 2001; Boisier, 2002; Berdegué, 2012). Así, no es solamente la acción pública municipal y provincial la que prima en la construcción de acciones territoriales, sino que también concurren otros actores de la acción privada y la acción pública, cada uno de ellos con su propia lógica y sus propios intereses (Sili, 2010).

Finalmente, se puede afirmar que el uso del concepto de acción territorial abre las puertas a pensar en las dinámicas de construcción del futuro de los territorios desde una perspectiva muy diferente, lejos de las premisas normativas sostenidas por el imaginario del desarrollo. Pensar la construcción del territorio desde una perspectiva de lo que los actores, en sus diferentes dimensiones escalares, realizan concretamente, permite entender los procesos tal como se dan en los territorios y por ende nos brinda mayor información para poder plantear proyectos de futuros más realistas, en función de las capacidades reales de los actores y no desde el imaginario del proyectista. 


\section{Referencias bibliográficas}

APPADURAI, A. El futuro como hecho cultural. Ensayos sobre la condición global. Buenos Aires: Fondo de Cultura Económica. 2015

BAUMAN, Z. Retrotopía. Buenos Aires: PAIDOS Estado y Sociedad. 2017

BERDEGUÉ, J. Territorios en Movimiento: Dinámicas Territoriales Rurales en América Latina. Santiago: Centro Latinoamericano para el Desarrollo Rural, Documento de Trabajo, 110 p. 2012.

BOISIER, S. La odisea del desarrollo territorial en América Latina. La búsqueda del desarrollo territorial y de la descentralización. En: SEMINARIO DESCENTRALIZACIÓN dE SECTORES SOCIALES: NUDOS CRÍTICOS ALTERNATIVAS, Lima. Ministerios de Educación y de Salud del Perú. 2002.

BOURDIEU, P. Capital cultural, escuela y espacio social. México: Siglo XXI. 2005

BRUNET, R., FERRAS, R \& THERY, H. Les mots de la Géographie, dictionnaire critique. Reclus - La Documentation Française, Collection Dynamiques du territoire. Paris. 1993.

BUSTOS CARA, R. Por una geografía de la acción territorial. En: Jornadas Cuyanas de Geografía, Mendoza: UNCUYO, 2008.

CEPAL (Comisión Económica para América Latina). The social inequality matrix in Latin America. Santo Domingo. 2016.

CROZIER, M.; FRIEDBERG, E. L'acteur et le système. Les contraintes de l'action collectif. París: Seuil. 1977.

DENTE, B.; SUBIRATS, J. Decisiones públicas: Análisis y estudio de los procesos de decisión en políticas públicas. Barcelona: Ariel. 2014.

DIEZ, J. I., \& URTIZBEREA, N. Redes institucionales y desarrollo económico en ciudades pequeñas. Eure, 41(0717-6236), 263-287. 2015.

DOUILLET, A., NÉGRIER, E., \& FAURE, A. Trois regards sur les politiques publiques vues du local. En Laurie Boussaguet ; Sophie Jacquot ; Pauline Ravinet. Une "French touch " dans l'analyse des politiques publiques?, Presses de Sciences Po, pp.319-348, 2015

FAURE, A. La question territoriale: pouvoirs locaux, action publique et politique(s). Grenoble: Cerat - Institut d'Etudes Politiques de Grenoble - Université Pierre Mendès France. 2008

FRANÇOIS, H.; HIRCZAK, M.; SENIL, N. Territoire et patrimoine: la coconstruction d'une dynamique et de ses ressources. Revue d'Economie Régionale et Urbaine, n. 5, p. 683-700, 2006.

GIDDENS, A. La Constitución de la Sociedad. Buenos Aires, Amorrortu. 1984. 
GRUENING, G. Origin and theoretical basis of new public management. International Public Management Journal, 4(1), 1-25. 2001.

GUMUCHIAN, H., LAJARGE, R.; GRASSET, E.; ROUX, E. Les acteurs, ces oubliés du territoire. Paris: Anthropos, 2003.

HARVEY, D. Ciudades rebeldes. Del derecho de la ciudad a la revolución urbana. Buenos Aires: Akal Pensamiento crítico, 2013.

IPARRAGUIRRE, G. Imaginarios del desarrollo. Gestión política y científica de la cultura. Bueno Aires: Editorial Biblos CULTURALIA. 2017.

KEBIR, L. Ressource et développement régional, quels enjeux? Revue d'Économie Régionale \& Urbaine, n. 5, p. 701-723, 2006.

KNIGHT, H. Institutions and social conflict. Nueva York: Cambridge University Press, 1992.

KNOEPFEL, P.; LARRUE, C.; VARONE, F.; DIECK, M. Hacia un modelo de análisis de políticas públicas operativo. Un enfoque basado en los actores, sus recursos y las instituciones. Ciencia Política, n. 3, p. 6-29. 2007.

LAJARGE, R. Le développement territorial ou comment satisfaire le besoin grandissant de territorialités multiples. Fonder les Sciences Territoriales, p. 128-132, 2011.

LANDEL, P.; PECQUEUR, B. L'operateur territorial, vecteur du changement. En: Colloque Association de Science régional de langue française, 2011.

MANZANAL, M.; PONCE, M. La desigualdad ¿del desarrollo?. Controversias y disyuntivas del desarrollo rural en el Norte argentino. Buenos Aires: Ed. Ciccus, 2012.

MASSON-VINCENT, M. Governance and geography explaining the importance of regional planning to citizens, stakeholders in their living space. Boletín de la A.G.E., n. 46, p. 363-367, 2008.

MOINE, A.; FAIVRE, E. Le territoire comme un système complexe : de la représentation á l'action. En 1'ere Conférence Intercontinentale d'Intelligence Territoriale : "Interdisciplinarité dans l'aménagement et développement des territoires", INTI-International Network of Territorial Intelligence. Octubre 2011, Gatineau, Canada. pp.8, 2013,

MONCAYO JIMÉNEZ, E. Evolución de los paradigmas y modelos interpretativos del desarrollo territorial. Santiago: Instituto Latinoamericano y del Caribe de Planificación Económica y Social. Gestión Pública, 13. 2001.

POUTHIER, F. Pourquoi et comment renouveler l'action territoriale aujourd'hui?. En: PIGNOT, L.; QUILES, J-P. (Coord.). Culture et Territoires : vers de nouvelles coopérations des acteurs artistiques et culturels. Paris: Librairie des Territoires, Éditions de l'OPC. p. 28-33. 2013. 
RIFFO, L. 50 años del ILPES: evolución de los marcos conceptuales sobre desarrollo territorial. Santiago de Chile: CEPAL (Desarrollo Territorial, 15). 2013.

SILI, M. La acción territorial: una propuesta conceptual y metodológica para su análisis. Revista Brasilera de Estudios Urbanos regionales. San Pablo, V.20, N.1, p.11-31, enero-abril 2018.

SILI, M. ¿Cómo revertir la crisis y la fragmentación de los territorios rurales? Ideas y propuestas para emprender procesos de desarrollo territorial rural. Buenos Aires: INTA. 2010.

SILI, M. Un modelo para comprender la dinámica de los territorios rurales. El caso de la Argentina. Mundo Agrario, v. 17, n. 34, e003, abril 2016.

SILI, M.; BUSTOS CARA, R.; GUIBERT, M. Atlas de la Argentina Rural. Buenos Aires: Capital Intelectual. 2015

SUBIRATS, J. (2008). Análisis de políticas públicas y gestión pública. Barcelona: Ariel. 2015.

SUBRA, P. L'aménagement, une question géopolitique. Hérodote, v. 130, n. 3, p. 222-250, 2008.

VANIER, M. Demain les territoires. Capitalisme réticulaire et espace politique. Paris: Hermannn. 2015.

\section{Anexo: Guía de entrevistas para el análisis de la acción territorial}

1) Podría mencionar hasta 5 fortalezas o recursos potenciales del Distrito de Saavedra (mencione en forma jerárquica)

2) Podría mencionar hasta 5 problemas o limitantes al desarrollo del Distrito de Saavedra (mencione en forma jerárquica)

3) ¿Cuál es para Uds. el escenario deseado de futuro para el Distrito?

4) ¿Qué acciones, planes, programas y proyectos que generan cambios se están llevando a cabo en el Distrito?

5) ¿Con qué recursos se llevan adelante estas acciones?

6) ¿Qué actores están involucrados en estas acciones?

7) ¿Cómo se organizan los actores y que vinculaciones generan para llevar adelante estas acciones?

8) ¿Qué resultados concretos surgen de las acciones que se están llevando a cabo?

9) ¿Cuáles son los factores que inhiben o limitan las acciones locales en marcha? 